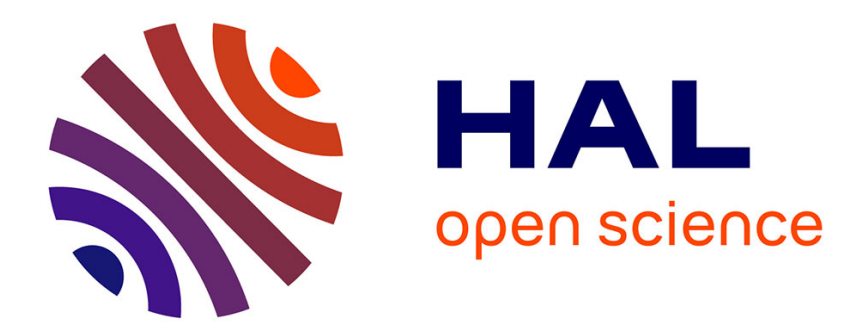

\title{
Protection of carbon based composites
}

M. Bacos

\section{To cite this version:}

M. Bacos. Protection of carbon based composites. Journal de Physique IV Proceedings, 1993, 03

(C9), pp.C9-819-C9-829. 10.1051/jp4:1993985 • jpa-00252427

\section{HAL Id: jpa-00252427 https://hal.science/jpa-00252427}

Submitted on 1 Jan 1993

HAL is a multi-disciplinary open access archive for the deposit and dissemination of scientific research documents, whether they are published or not. The documents may come from teaching and research institutions in France or abroad, or from public or private research centers.
L'archive ouverte pluridisciplinaire HAL, est destinée au dépôt et à la diffusion de documents scientifiques de niveau recherche, publiés ou non, émanant des établissements d'enseignement et de recherche français ou étrangers, des laboratoires publics ou privés. 


\title{
Protection of carbon based composites (*)
}

\author{
M.P. Bacos \\ Office National d'Etudes et de Recherches Aérospatiales, Direction des Matériaux, B.P. 72, 92322 \\ Chatillon Cedex, France
}

\begin{abstract}
Based on their good mechanical properties, potential uses of structural carbon materials have been identified for future manned hypersonic vehicles and other aircraft applications. Carbon based composites are expected to be used for periods ranging from a few hours (at high temperature) to a few thousands of hours (at low temperature) in oxidizing environments. Unfortunately carbon reacts rapidly with oxygen at temperature as low as $500{ }^{\circ} \mathrm{C}$. Therefore numerous researches have been conducted in an attempt to protect carbon-carbon composites against oxidation. The protection mechanism relies on different concepts depending on the temperature range. Two different basic approaches have been considered to protect carbonaceous materials: 1) a microscopic one (at low temperature) using poisoning agents which adsorb on the active sites responsible for the carbon gasification; and 2) a macroscopic one (at high temperature) using an oxygen barrier. But the difference in thermal behavior that exists between this layer and the carbon substrate results in coating cracks. Therefore other approaches have been developed including: a) transition layer; b) inhibited matrix; c) coating on fibers. Temperature, pressure and oxidizing atmospheres limitations of all theses concepts are discussed. Typically, protection for extended periods can be achieved in a limited range of pressure and temperature by the use of several concepts and multilayer coating.
\end{abstract}

\section{Introduction.}

Structural carbon materials in the form of carbon fiber-reinforced carbon matrix or carboncarbon composites are gaining increasing importance because of their high toughness, high strength and low weight. In a non oxidizing environment, carbon fibers retain their modulus, strength and their high mechanical properties to high temperatures. Based on their good mechanical performances, potential uses of structural carbon materials have been identified in future manned hypersonic vehicles (Hermes, Sänger, Hotol) and in other aircraft applications. However most of these applications involve extended time periods in oxidizing atmospheres. Unfortunately, carbon-carbon composites react rapidly with oxygen at temperatures as low as $500^{\circ} \mathrm{C}$ and are subject to oxidation degradation. Therefore, numerous researches have been conducted in an attempt to protect carbon based composites against oxidation.

The protection mechanism relies on different concepts depending on the temperature range. Two different basic approaches have been considered to protect carbonaceous materials:

1) a microscopic one (at low temperature) with the use of poisoning agents which adsorb on the active sites responsible for the carbon oxidation gasification;

2) a macroscopic one with the use of a barrier against oxygen diffusion at high temperature.

(*) Keynote lecture. 
Due to the desorption of adsorbed poisoning agents and the increase of the number of active sites, the first concept cannot be used above $900^{\circ} \mathrm{C}$.

The main problem, when applying the second concept, is the thermal mismatch between coating and carbon substrate which results in cracking of the coating. Therefore other approaches have been developed including:

1) intermediate layer;

2) inhibited matrix;

3) fiber protection.

The purpose of this work is to evaluate the inherent limitations of the various approaches being considered and to summarize most of published work being realized.

For this discussion, we assume that good mechanical properties are preserved for a mass loss below $3 \%$, and we define short, middle and long-term applications according to the time (15 minutes, 15 hours and 100 hours respectively) needed to reach this mass loss.

\section{Protection by active sites poisoning.}

Crystalline graphite may be considered as a model compound for the carbon-carbon composites. In a graphite lattice (Fig. 1) edge atoms are more reactive than basal atoms and are the main active sites. On the edge of layer planes, two types of active sites are present: zigzag sites (with alternate labile carbon atoms) and arm-chair sites (with adjacent labile carbon atoms) (Fig. 1). Others active sites may exist including point defects and screw dislocations. Below $900^{\circ} \mathrm{C}$, gasification from molecular oxygen attack on carbon is dominated by the oxidation of zig-zag sites [1]. Therefore, adsorption of poisoning agents on these sites should inhibit the reaction.

ARH-CHAIR FACE

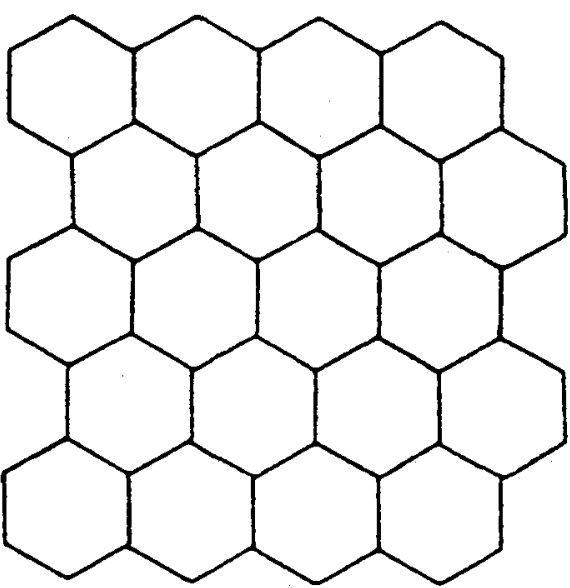

Active sites

Fig. 1. - Graphite crystal lattice. 
Three types of poisoning agents (or active site passivators) have been studied: halogens, boron compounds and phosphorus compounds. Pretreatment with liquid organohalogen compounds is not effective [2], due to their desorption from the carbon surface at temperatures as low as $100-300^{\circ} \mathrm{C}$. The pretreatment with gaseous chlorine is more effective, but halogen atoms are desorbed about above $900{ }^{\circ} \mathrm{C}$ [2-6]. Bromination [7-9] was found to increase the oxidation resistance of poorly graphitized carbon fibers but caused physical damage in more graphitic fibers by decreasing their oxidation resistance. Stronger poisoning effects were observed with phosphorus compounds [10-12] or organo-borates and boron oxide $[13,14]$ which adsorbed on "zig-zag" sites. But these adsorbed radicals also enhanced adsorption of water, and therefore, this type of protection is effective only in dry atmosphere. Some silicious compounds have been tested [15, 16], but a complete blockage of the active sites is not achieved due to the large size of the molecules [15].

Experimental published results indicate that the maximum temperatures up to which poisoning agents are effective are $600^{\circ} \mathrm{C}$ and $750^{\circ} \mathrm{C}$ for middle and short-term dry applications respectively.

At higher temperatures, this protection concept is no more valid due to the increase of the diversity of active sites and reactional mechanisms. Theoretical calculations, carried out by Luthra [72], indicated that maximum temperatures, which could be reached with stronger poisoning agents, are $600^{\circ} \mathrm{C}$ and $900^{\circ} \mathrm{C}$ for middle and short-term applications. Therefore, for higher temperatures, the concept of oxidation protection by coating has been developed.

\section{Coatings.}

3.1 OXYGEN BARRIER LAYER. - Desired properties for the coatings on carbon-carbon composites are thermal expansion compatibility (Fig. 2) to minimize cracks, low oxygen and carbon diffusion, low vapor pressure, chemical compatibility with carbon, erosion, wear and impact resistance.

The main coatings studied are based on noble metals, phosphates, boron, oxides, carbides, silicides.

3.1.1 Noble metals. - Refractory group metals, such as iridium and ruthenium, are potential elements for oxidation protection systems of carbon-carbon [16, 18]. Iridium has a high melting point $\left(2447^{\circ} \mathrm{C}\right)$, a very low oxygen permeability and is chemically compatible with carbon (formation of an eutectic at $2110^{\circ} \mathrm{C}$, no carbide formation). However, its high thermal expansion coefficient (TEC), poor adherence to carbon materials, erosion via volatile oxidation, high cost and short supply limit its use [18-21]. At the present time, iridium is used in multilayer coating concept [22] (Chap. 5).

3.1.2 Phosphate coatings. - Many phosphate coatings have been studied for the oxidation protection systems. They include aluminium [23], magnesium [23], ternary compounds [24], alkali and alkaline metals [25]. They are usually either mixed with ceramic powders [25] or applied on a transition layer such as $\mathrm{SiC}$ [23]. But they can only be used at low temperatures (up to $850^{\circ} \mathrm{C}$ ) in a dry atmosphere for short-term applications.

3.1.3 Boron-based coatings. - Boron oxide is an attractive compound for the protection against oxidation. The chemical compatibility of $\mathrm{B}_{2} \mathrm{O}_{3}$ with carbon, its good wetting property and its low viscosity $\left(10^{4}\right.$ to $10^{2} \mathrm{dPa}$ in the $600-1100^{\circ} \mathrm{C}$ range) allow the formation of thin protective glass films $[19,26-28]$. Under dry conditions, borate glass coatings can be used up to $600^{\circ} \mathrm{C}$ and $1000^{\circ} \mathrm{C}$ for long and short-term applications respectively [19, 72]. 


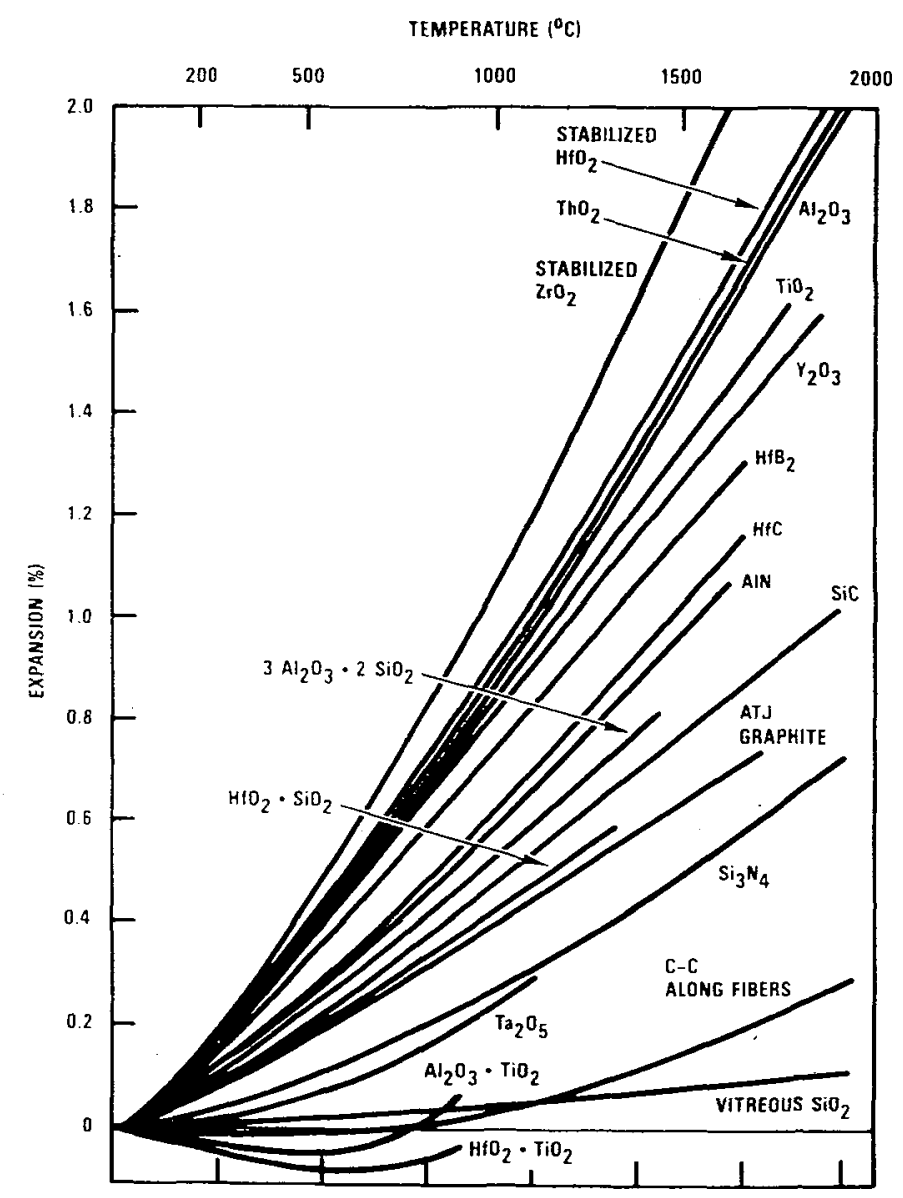

Fig. 2. - Percent thermal expansion as a function of temperature for some ceramic materials and carbon fibers according [48].

The main limitations of borate glasses are their moisture sensitivity [29] (hydrolysis under ambiant conditions) and at higher temperatures the vaporisation of boron oxide [26].

3.1.4 Oxides. - Oxides have numerous advantages but generally they have too large thermal expansion coefficient (TEC) $[19,20,30-33]$. Therefore, it is very difficult to apply crack-free coatings. Other limitations are due to:

- fast oxygen diffusion through oxides phase (for instance $\mathrm{ZrO}_{2}, \mathrm{HfO}_{2}$ have high oxygen permeability);

- oxide reduction by the carbon (as low as $1200^{\circ} \mathrm{C}$ for silica, $1730^{\circ} \mathrm{C}$ for $\mathrm{ZrO}_{2}, 1750{ }^{\circ} \mathrm{C}$ for $\mathrm{HfO}_{2}$ ).

- total gas pressure at the oxide-carbon interface causing spallation ( 1 atmosphere at $1500^{\circ} \mathrm{C}$ for the silica/carbon system).

Therefore direct oxide deposit on carbon must be avoided. Oxide are generally used as the upper layer (oxygen barrier layer) in multilayer coatings. 
3.1.5 Siticides. - Molybdenum disilicide coatings have been used for the oxidation protection [34] but these compounds react with carbon and have a high TEC. Therefore an intermediate layer to isolate them from carbon is needed.

3.1.6 Silicon carbide and silicon nitride. - Silicon carbide and silicon nitride are the best candidates for the oxidation protection of carbon. The thermal expansion coefficient (TEG) of these compounds and of silica is near the TEC of the carbon-carbon composites (Fig. 2). In spite of this good adequation, it is difficult to form coatings without cracks. Therefore at low temperatures, $\left(T<1250^{\circ} \mathrm{G}\right.$ ) (domain I, Figs. 3 and 4), it works only for short-term

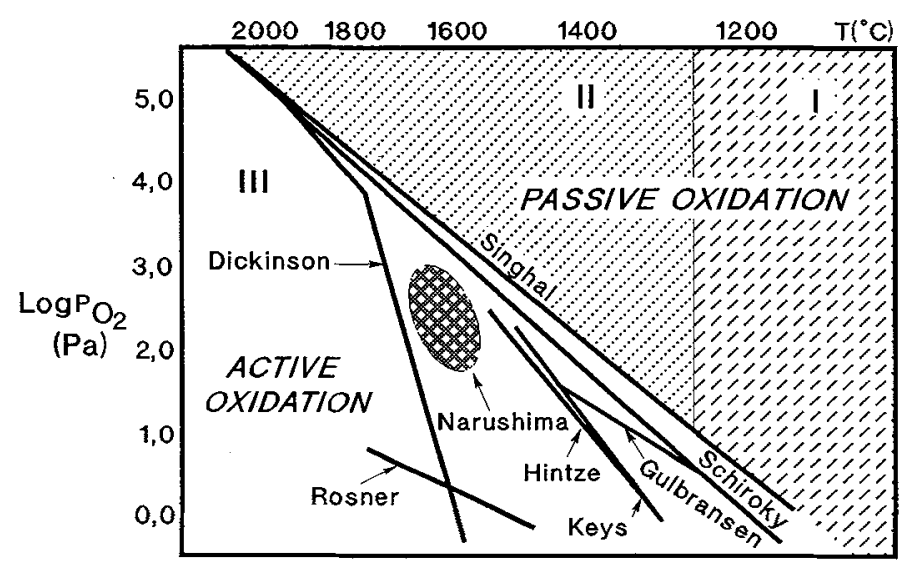

Fig. 3. - Literature data for the active-to-passive oxidation transition for SiC according to [51].

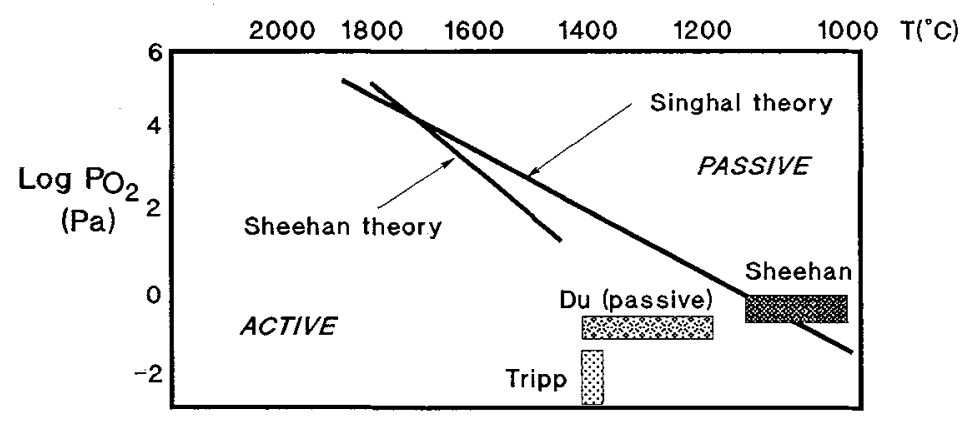

Fig. 4. - Literature data for the active-to-passive oxidation transition for $\mathrm{Si}_{3} \mathrm{~N}_{4}$ according to [51].

application [39]. At higher temperatures (domain II, Figs. 3 and 4) due to the formation of low viscosity silica, it works for middle-term application. At very high temperatures or middle temperatures and low oxygen pressures (domain III, Figs. 3 and 4), silica does not protect 
anymore because of the formation of gaseous silicon monoxide by [40-52]:

- active oxidation

$$
\begin{aligned}
& \mathrm{SiC}+\mathrm{O}_{2} \rightarrow \mathrm{SiO}+\mathrm{CO} \\
& \mathrm{Si}_{3} \mathrm{~N}_{4}+3 / 2 \mathrm{O}_{2} \rightarrow 3 \mathrm{SiO}+2 \mathrm{~N}_{2}
\end{aligned}
$$

- $\mathrm{SiC} / \mathrm{SiO}_{2}$ reaction

$$
\mathrm{SiC}+2 \mathrm{SiO}_{2} \rightarrow 3 \mathrm{SiO}+\mathrm{CO}
$$

- $\mathrm{Si}_{3} \mathrm{~N}_{4} / \mathrm{SiO}_{2}$ reaction

$$
\mathrm{Si}_{3} \mathrm{~N}_{4}+3 \mathrm{SiO}_{2} \rightarrow 6 \mathrm{SiO}+2 \mathrm{~N}_{2}
$$

3.1.7 Metal carbides. - Metal (zirconium, hafnium, titanium, tantalum, tungsten) carbides have very high TEC [35] and their oxides have high oxygen permeability. Therefore they are generally used in the temperature-pressure domain where the silicon carbide coating is not valid [36, 37] (chap. 3.1.6).

Chromium carbide deposits have been claimed to increase the oxidation resistance [38] but the stoichiometry of this carbide was not specified.

3.1.8 Composite coatings. - In order to adjust the coatings properties to the substrates, composite coatings have been developed. For instance, yttria-stabilized zirconia containing $\mathrm{SiC}$ whiskers [33], zirconium carbide and boron nitride [53], hafnium and silicon [54] have been deposited on carbon or carbon-carbon composites.

3.1.9 Conclusion. - The most common failure mechanism of a coating is its spallation due to the thermal expanision mismatch with the $\mathrm{C} / \mathrm{C}$ substrate. To minimize the cracks, transition layers have been developed. Another way to protect the composite, and to limit the effects of cracks, is the use of glass formers (inhibited matrix) which are able to form mobile glass which spreads within the cracks.

3.2 TRANSITION LAYERS. - Carbide conversion layers improve surface cohesive strength. They are used beneath the outer coatings in particular for long or middle-term applications [36, 55-59, 63-65] (chap. 5). Most of the transition layers are made by a pack cementation process [60-61], and sometimes these layers are (boron or zirconium) doped [62]. This double protection (transition layer and outer coating) is efficient up to $1000^{\circ} \mathrm{C}$ and $1600^{\circ} \mathrm{C}$ for middle and short-term applications in a dry atmosphere.

Other intermediate layers such as porous CVD silicon layer [66] or graded coatings [53] have been developed but seem less effective.

Physical methods such as (boron) ion implantation have also been tested [53] in order to reduce oxidation rate at low temperature.

3.3 INHIBITED MATRIX. - The oxidation protection concept with the use of a layer barrier is not valid when the damage probabilities are great (meteorite impact ...). Therefore a new approach has been developed by adding in the carbon precursor some glass formers which are able to spread within the cracks $[38,65,67-71]$. The most components studied are $\mathrm{B}_{4} \mathrm{C}, \mathrm{B}$, $\mathrm{CrB}_{2}, \mathrm{ZrB}_{2}, \mathrm{SiB}_{4}, \mathrm{AlB}_{12}, \mathrm{ZrH}-\mathrm{Si}, \mathrm{ZrB}_{2}-\mathrm{Si}$, SiC, phosphates. With only inhibited matrix, $\mathrm{C} / \mathrm{C}$ composites can be used up to $800^{\circ} \mathrm{C}$ and to $1000^{\circ} \mathrm{C}$ for middle and short-term applications 
respectively. This type of protection is generally used in addition to other protection systems $[36,55,59,63-65]$.

\section{Coatings on fibers.}

In order to protect the carbonaceous fibrous reinforcement, several coatings have been developed. Most of them have been applied by chemical vapor deposition [76-77] and by sol-gel methods [78].

\section{Complex systems and multi-layer coatings.}

In many aerospace applications, the desired properties of $\mathrm{C} / \mathrm{C}$ composites are thermal stability, thermal shock resistance, oxidation resistance under thermal cycling conditions in a 1 atmosphere air pressure or in a partial pressure of molecular or atomic oxygen, resistance to degradation by moisture, resistance to rain erosion, high emittance and multi mission reliability.

In order to reach this objective, many complex systems have been developed including: coatings on fibers, inhibited matrix, transition layer, coating and outer glass sealant [73] (Fig. 5). Most of these oxidation protection systems contain SiC CVD coating on fibers, boron

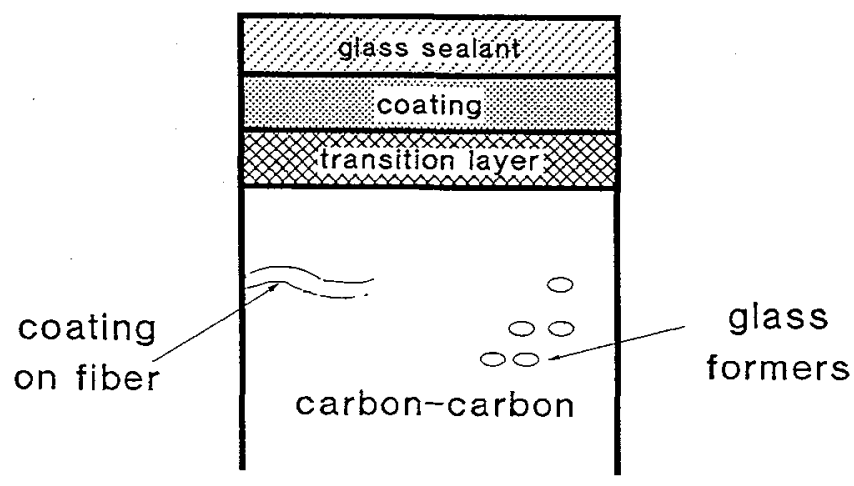

Fig. 5. - Oxidation protection system according [73].

or silicon carbide in matrix, silicon carbide converted layer, silicon carbide CVD coating and outer silica (or borosilica) glass [51,63-66, 73]. Another complex system has been studied by Bavarian et al. (Fig. 6). The protection is composed of a pyrolithic CVD carbon layer, a mixed hafnium carbide and hafnium disilicide layer and an outer silicon carbide layer. Unfortunately, these systems based on silicon carbide are not effective beyond $1800^{\circ} \mathrm{C}$ in a dry atmosphere due to the active oxidation of silicon carbide (chap. 3.1.7). Moreover, in a humid atmosphere, this type of protection (which includes boron protection, as glass formers in the matrix or component of the outer glass) can only work up to $1100^{\circ} \mathrm{C}$ for middle-term applications. Indeed, moisture absorption and subsequent rapid gas formation during heating led to the spallation of the coating from the substrate [73]. 


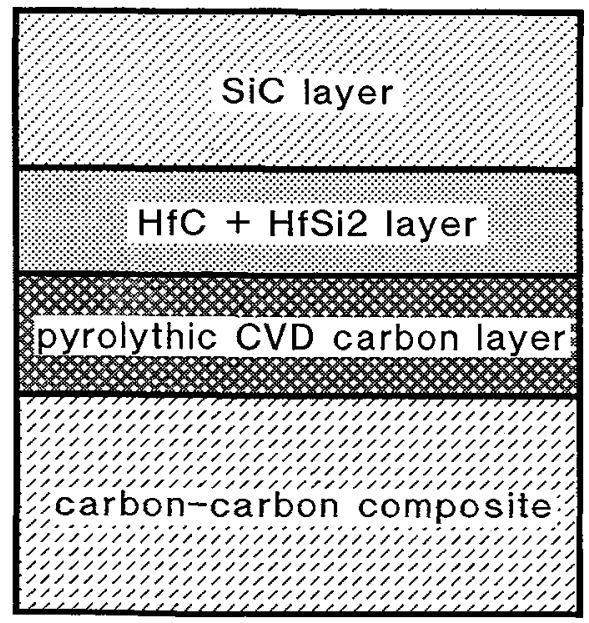

Fig. 6. - Protective system proposed by Bavarian [54].

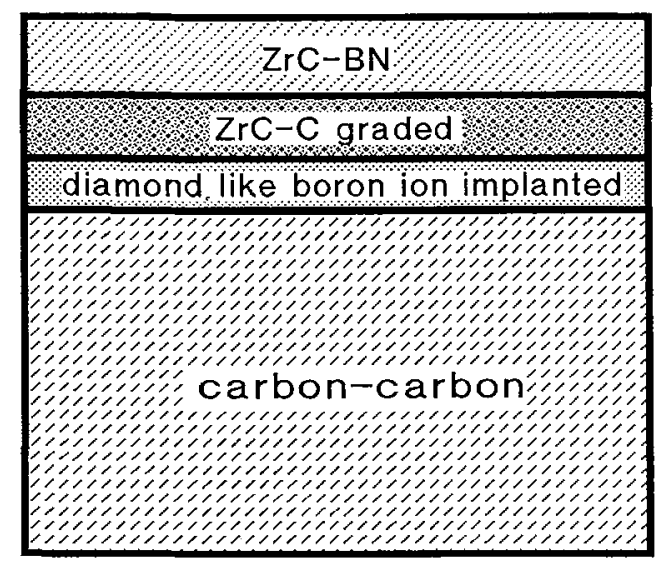

Fig. 7. - Protective system proposed by Kowbel [53].

Other oxidation protections have been developed for high temperature and low gas pressure applications. Aerospatiale claims a double layer protection $\mathrm{AlN} / \mathrm{Al}_{2} \mathrm{O}_{3}[74,75]$. Kowbel developed a system with the following features: a first diamond-like coating boron ion implanted, a second graded CVD ZrC-C layer and an outer mixed coating ZrC/BN [53] (Fig. 7). Fischbach [22] studied another complex system with an inner layer of a carbide-forming metal (Al, Hf, $\mathrm{Zr}$ ), an impermeable metal barrier layer (Ir, Ru), and an outer layer of stable metal oxide former (Al, $\mathrm{Hf}, \mathrm{Zr}$ ). 


\section{Conclusion.}

At present, many advanced oxidation protection systems have been developed but there is no universal solution for the general problem of protecting carbon-carbon against oxidation. The use of poisoning agents allows carbon-carbon to be protected up to $600^{\circ} \mathrm{C}$ and $750{ }^{\circ} \mathrm{C}$ for middle-term applications and short-term applications respectively. At higher temperatures, external barrier layer must be used. However, due to the TEC mismatch between the coating and the substrate, oxidation protection must also include glass formers in the matrix, coatings on fibers, transition layers, oxygen barrier layer (carbide and nitride), outer glass sealant. With siliceous coatings, oxidation protection works up to $1800^{\circ} \mathrm{C}$ in a dry atmosphere ( 1 bar) for middle-term applications. At higher temperatures or lower pressures, this system fails due to the active oxidation of silicon carbide. Boron compounds are good glass formers and used as outer glass sealants but they are too moisture sensitive which reduces the oxidation protection to middle-term applications up to $1100^{\circ} \mathrm{C}$. Thereby, there is a need for oxidation protection systems which are not moisture sensitive and which can work above $1800^{\circ} \mathrm{C}$ for long term applications. It is possible that graded coatings and mixed layers could be developed with this objective in mind.

\section{References}

[1] Henning G.R., Chemistry and Physics of Carbon, Vol. 2, P.L. Walker Jr Ed. (1975) p. 1.

[2] MC KeE D.W., Carbon 23 (1985) 347.

[3] PURI B.R., Carbon 5 (1967) 189.

[4] PURI B.R., Indian. J. Chem. 5 (1967) 381.

[5] TOBIAS H., Carbon 23 (1985) 281.

[6] ASHER R.C., J. Nuclear. Mater. 25 (1968) 344.

[7] CHIOU J.M., Carbon 27 (1988) 227.

[8] Ho C.T., Carbon 28 (1990) 521.

[9] Ho C.T., Carbon 28 (1990) 815.

[10] Magne P., Bull. Soc. Chim. France 6 (1971) 2005.

[11] MC. KEE D.W., Carbon 10 (1972) 491.

[12] MC KEE D.W., Carbon 22 (1984) 285.

[13] MC KEE D.W., Carbon 22 (1984) 507.

[14] EHRburger P., Carbon 24 (1986) 495.

[15] EHRbURGer P., Fundamental issues in control of carbon gasification reactivity, Vol. 192, J.Lahaye, P. Ehrburger Eds. (NATO ASI Series E, 1991) p. 461.

[16] MC KEE D.W., ibid, p. 485.

[17] Rosnet J.Ph., Thèse, Université de Lille (1990).

[18] Criscione J.M., ML-TDR-64-173, Part II (1974).

[19] SHEEHAN J.E., Carbon 27 (1989) 709.

[20] GRENIÉ Y., Aérospatiale, NT n 89/88 AQEM/R (1989).

[21] JEHN H., J. less-Common. Met. 100 (1984) 321.

[22] FischbaCH D.B., Proceedings of the $20^{\text {th }}$ Biennal Conf. on Carbon (Santa Barbara, CA, 1991) p. 412.

[23] WEIL W.M., French patent., 1,446,038. 
[24] VAST P., Proc. Carbon (New Castle, U.K., 1988) p. 582.

[25] Chakraborty S., J. Mater. Sci. Lett. 8 (1989) 1358.

[26] MC KEE D.W., Carbon 24 (1986) 737.

[27] KAEE J.L., AFOSR-TR-88-0284 (1988).

[28] INAGAKI M., Carbon 29 (1991) 287.

[29] Chang C.E., Mater. Res. Bull. 6 (1971) 1287.

[30] STRIFFE J.R., Ceram. Bull. 67 (1988) 369.

[31] BACOS M.P., $4^{\text {th }}$ International Symp. sur "les matériaux utilisés en ambiance spatiale" (Toulouse, 1988).

[32] SIM S.M., Symposium on better ceramics through chemistry (Palo Alto, U.S.A., 1986).

[33] SIM S.M., Ultrastructure processing of advanced ceramics (Gainesville, Florida, U.S.A., 1983) p. 995.

[34] Fitzer E., $4^{\text {eme }}$ Conf. Int. sur les carbones et les graphites (Londres, U.K., 1974).

[35] Lackey W.J., Ceram. Eng. Sci. Proc. 9 (9-10) (1988) 1223.

[36] CHown J., Specials Ceramics, Popper Ed. (1962).

[37] DENTZER J.R., SAMPE Q. 2 (1971).

[38] HAN K.H., J. Electrochem. Soc. 134 (1987) 1003.

[39] Dimitrijevic S.T., Proceedings of the $20^{\text {th }}$ Biennal Conf. on Carbon (Santa Barbara, CA, 1991).

[40] KeYS L.H., Proceedings of the symposium on properties of high temperature alloys, Vol. 77 (The Electrochemical Society, Princeton, 1977).

[41] Gulbransen E.A., J. Electrochem. Soc. 113 (1-6) (1966) 1311.

[42] HinZE W., J. Electrochem. Soc. 123 (1976) 1066.

[43] NARUshima T., Proceedings of the international meeting on advanced materials, Vol. 4 (Pittsburgh, 1989).

[44] SCHIROKY G.H., GA-Al8696 (1986).

[45] SHingal S.C., Proceedings of the symposium on properties of high temperatures alloys with emphasis on environmental effects, Vol. 77( 1), Z.A. Faroulis Ed. (1976).

[46] DICKINSON R.C., Proceedings of the oxidation resistant C/C composites for hypersonic vehicles application (workshop, Hampton, VA, NASA conference publication 2501, 1987).

[47] Rosner D.E., J. Phys. Chem. 74 (1970) 1829.

[48] Sheehan E., J. Am. Ceram. Soc. 65 (1982) C-111.

[49] Du H., Ph.D. thesis, Pennsylvania State University (PA, 1988).

[50] Tripp W.C., J. Am. Ceram. Soc. 59 (9-10) (1976) 399.

[51] Vaughn W.L., J. Am. Ceram. Soc. 73 (1990) 1540.

[52] Heuer A.H., J. Am. Ceram. Soc. 73 (1990) 2785.

[53] Kowbel W., Proceedings of the Third Int. Symp. on Ceramic Materials and Components for Enginer (Las Vegas, 1988).

[54] BAVARIAN B., Proceedings of the $35^{\text {th }}$ International Sampe Symposium, book 2 (1990) p. 1348.

[55] FATZER E.G., US Patent, 3,925,577 (1975).

[56] MileWSKI J.V., US Patent, 2,528,823 (1983).

[57] GaLASSO F.S., US Patent, 4,425,407 (1984).

[58] VELTRI R.D., US Patent, 4,476,178 (1984).

[59] PATTEN J.W., US Patent, 4,500,602 (1985).

[60] Rogers D.C., Proceedings of the $7^{\text {th }}$ National Sampe Technical Conference, Vol. 7 (Albuquerque, 1975).

[61] KLEPPING A.H., AIAA-86-1499 (1986). 
[62] BARRET D.M., Proceedings of the ASC Symposium on High Temperature Composites (Dayton, 1989) p. 282.

[63] STROUd C.W., NASA TM 81799 (1980).

[64] ROUSSEAU G., Brevet Européen 0.282.386 Al (1988).

[65] Cullinan J., AFOSR-86-0251 (1990).

[66] KINJo T., Kawasaki steel techn. report 23 (1990) 54.

[67] JAWED I., Mater. Res. Bull. 21 (1986) 1391.

[68] MC KEE D.W., Carbon 26 (1988) 659.

[69] MC KEE D.W., Carbon 24 (1986) 331.

[70] SHAFFER R.C., US Patent 4,321,298 (1982).

[71] VASILOS, US Patent, 4,426,600 (1982).

[72] LUTHRA K.L., Carbon 26 (1988) 217.

[73] Eitman D.A., Gas Turbine and Aeroengine Congress and Exposition (Toronto, 1989).

[74] Rousseau G., Brevet Européen 0.359.614. Al (1989).

[75] FRANC O., Space Applications of Advanced Structural Materials (Noordwijk, NL, 1990).

[76] KILIN V.S., Moscow translated from Poroshk. Metall. 2 (146) (1975) 44.

[77] VINCENT H., Third European Conference on Composite Materials (Bordeaux, 1989) p. 257.

[78] Deslandes Y, J. Mater. Sci. Lett. 9 (1990) 200. 